\title{
The rational use of antibiotics: The Princess Margaret Hospital experience
}

George Dranitsaris MSc Phm, Kelly MacDonald MD, Allison McGeer MD

$\mathrm{I}^{\mathrm{n}}$ $\mathrm{n}$ the past decade, there has been an alarming trend towards increased antimicrobial resistance in many human pathogens. Of the many possible factors responsible for these developments, the overuse and inappropriate prescribing of broad-spectrum antibiotics has been implicated (1). Rational, cost effective drug use needs to be promoted to begin controlling this problem. A structured drug use evaluation (DUE) process involving clinical pharmacists, staff physicians and infectious disease (ID) specialists has been reported to be effective in promoting appropriate drug prescribing (2). During the past 20 years, hospital-based retrospective and prospective DUE studies have played an integral role in health care delivery. Retrospective DUE involves an analysis of drug use after therapy has been administered. Prospective studies usually begin with the development of guidelines for the appropriate use of the agent in question $(2,3)$. A formal evaluation process is initiated where pharmacists monitor drug therapy over a specified period of time. Interventions necessary to correct inappropriate prescribing patterns are then implemented before therapy is administered. The results of such studies are usually presented as the proportion of drug orders meeting guidelines following the intervention.

The primary objective of many DUE studies is to improve physician prescribing within a set of hospital-approved guidelines for drug use. Theoretically, this should reduce the annual usage of broad-spectrum antimicrobials, thereby limiting the development of antimicrobial resistance. The DUE approach has demonstrated its ability to alter physician prescribing patterns in several drug classes, such as antiemetics, $\mathrm{H}_{2}$-receptor antagonists and antimicrobials (4-6). In one report, Lazor-Bajcar and Fowler (7) conducted a prospective
DUE on the use of intravenous metronidazole in a community hospital. In that study, an initial retrospective audit of metronidazole determined that approximately $50 \%$ of all prescriptions did not meet hospital guidelines. A pharmacist-driven intervention program was initiated for all orders outside of the guidelines. Subsequent drug use within hospital guidelines increased to $86 \%$, and there was an annual reduction in intravenous metronidazole usage by approximately $70 \%(7)$.

\section{THE ANTIBIOTIC PROCESS AT THE PRINCESS MARGARET HOSPITAL}

Successful implementation of any formal antibiotic monitoring program requires a strong antimicrobial subcommittee and a committed, credible clinical pharmacy department. At the Princess Margaret Hospital (PMH), this subcommittee consists of an ID specialist (chair), a hematologist, physicians from the departments of medical and radiation oncology, and three pharmacists. This group is responsible for advising the Pharmacy \& Therapeutics Committee about antimicrobial formulary issues, monitoring antibiotic consumption patterns, developing antibiotic usage guidelines, educating physicians, overseeing the implementation of formal DUE studies and conducting pharmacoeconomic analyses.

The subcommittee actively participates in multicentre studies and initiates institutional clinical trials of new antimicrobials. The objective of these institutional studies has been to allow a centre-specific clinical and prospective economic evaluation of new agents. In addition, staff physicians gain personal experience with the drug before formulary entry, and agents are evaluated under routine hospital conditions. Therefore, when a final formulary decision is made, comprehensive

Departments of Pharmacy and Microbiology, Ontario Cancer Institute/Princess Margaret Hospital and Mount Sinai Hospital, Toronto, Ontario

Correspondence and reprints: Dr Kelly S MacDonald, Department of Microbiology, Mount Sinai Hospital, 1484-600 University Avenue, Toronto, Ontario M5G 1X5. Telephone 416-586-8879, fax 416-586-8746, e-mail kmacdonald@mtsinai.on.ca 
clinical and economic information can be presented to the Pharmacy \& Therapeutics Committee.

A primary responsibility of the antimicrobial subcommittee is to develop guidelines for the rational use of antibiotics. Adopting an evidence-based medicine approach, guidelines are designed to be practical and 'user friendly', and to promote rational antibiotic prescribing. A fundamental requirement during this development phase is to solicit the input of key institutional physicians, thus creating a sense of ownership. In addition, clinical pharmacists are asked for their comments because they ultimately will be implementing the usage criteria.

However, guidelines are of limited value without an active mechanism for implementation $(3,8)$. Clinical pharmacists have been found to be highly effective in ensuring that physician prescribing complies with hospital-approved guidelines $(4,7,8)$. The prospective monitoring of prescribing by unit pharmacists through a formal DUE program has been very successful $(4,9,10)$. In the first five years of the program, some of the drugs that were prospectively monitored were vancomycin, ceftazidime, acyclovir and ciprofloxacin $(9,10)$. Overall, we managed to improve physician prescribing within institutional guidelines and reduce hospital expenditures (9-11). In addition, the antimicrobial subcommittee was able to implement successfully a cost effective strategy for the empirical management of cancer patients with febrile neutropenia (12). As a result, empirical vancomycin and ceftazidime usage substantially decreased throughout PMH $(9,10)$.

The committee has been responsible for the promotion of pharmacoeconomic evaluations of antimicrobial agents in cancer patients (11-13). The objectives of these studies have been to identify antibiotic usage strategies that would maintain or improve the quality of patient care and save antibiotic costs. The Antimicrobial Subcommittee is currently conducting a prospective clinical and economic evaluation of empirical cefepime therapy in patients with febrile neutropenia. If the results of this study suggest that cefepime has signifi-

\section{REFERENCES}

1. Gaynes R, Monnet D. The contribution of antibiotic use on the frequency of antibiotic resistance in hospitals. Ciba Foundation Symposium 1997;207:47-56.

2. Hoffman RP. A strategy to reduce drug expenditures with a drug utilization review program. Hosp Pharm 1984;19:7-12.

3. Blackburn JL. Impact of drug usage review on drug utilization. Pharmacoeconomics 1993;3:14-21.

4. Dranitsaris G, Warr D, Puodziunas A. A randomized trial of the effects of pharmacist intervention on the cost of antiemetic therapy with ondansetron. Support Care Cancer 1995;3:183-9.

5. Kirking DM, Svinte MK, Berardi RB, Cornish LA, Chaffee BW, Ryan ML. Evaluation of direct pharmacist intervention on conversion from parenteral to oral histamine $\mathrm{H}_{2}$-receptor antagonist therapy. Ann Pharmacother 1991;25:80-4.

6. Bamberger DM, Dahl SL. Impact of voluntary vs enforced compliance of third-generation cephalosporin use in a teaching hospital. Arch Intern Med 1992;152:554-7.

7. Lazor-Bacjar LM, Fowler R. The development and implementation of a drug utilization review program. Can J Hosp Pharm 1988;41:11-6.

8. Lipton HL, Byrns PJ, Soumerai SB, Chrischilles EA. Pharmacists as agents of change for rational drug therapy. Int J Technol Assess Health Care 1995;11:485-508. cant economic advantages with equivalent efficacy compared with ceftazidime, it would become the hospital's primary broad-spectrum cephalosporin. Similar proposals are under development for other agents such as liposomal amphotericin $\mathrm{B}$.

Clinical trials are the most effective method of acquiring knowledge about antimicrobial agents in the unique oncology patient population we treat. An important role of the antimicrobial subcommittee at the PMH has been to conduct clinical trials, with a member of the committee acting as the principal investigator. From this vantage point, the antimicrobial subcommittee is able to design studies that maximize the benefit for our patients, bring in important research funding to the institution and contribute to the literature through publication in peer-reviewed journals. In recent months, the Antimicrobial Subcomittee has also become involved in a study to assess acute care institution continuous usage patterns across Ontario for the purpose of preventing the development of resistant microorganisms. Preliminary results suggest that the consumption of intravenous ciprofloxacin and vancomycin in acute care hospitals in Ontario has been steadily increasing from 1993 to 1997 (14). This phenomenon was observed despite stable hospital admission rates.

\section{CONCLUSIONS}

The widespread use of antibiotics since the end of World War II has had a tremendous impact on reducing patient mortality and morbidity; however, the 'attractiveness' of these agents has also contributed to their inappropriate use and overprescription. As a result, microorganisms have developed resistance to many of these agents. Hospital formulary committees must be actively involved in educating physicians and promoting rational drug use within a set of medically approved guidelines to decrease these negative developments. Through these processes, PMH has limited the use of broad-spectrum antibiotics to hospital-approved indications, reduced hospital costs and improved patient care.

9. Puodziunas A, Dranitsaris G, McGeer AJ. Vancomycin drug use evaluation in a cancer hospital: Impact of pharmacist intervention on prescribing. Can J Hosp Pharm 1994;47:83.

10. Dranitsaris G, McGeer AJ, Puodziunas A. Ceftazidime drug use evaluation in a cancer hospital: Impact of pharmacist intervention on prescribing. Can J Hosp Pharm 1994;47:46.

11. Dranitsaris G, Pilla NJ, McGeer AJ. A vancomycin drug use evaluation and economic analysis in a cancer treatment centre. Can J Hosp Pharm 1994;47:59-64.

12. Dranitsaris G, Tran TM, McGeer AJ, Narine L. Pharmacoeconomic analysis of empiric therapy with ceftazidime alone or combination antibiotics for febrile neutropenia in cancer patients. Pharmacoeconomics 1995;7:49-62.

13. Dranitsaris G, Phillips P, Rotstein C, et al. Economic analysis of fluconazole versus amphotericin B for the treatment of candidemia in non-neutropenic patients. Pharmacoeconomics 1998;13:509-18.

14. Dranitsaris G, Brooks J, McGeer A, et al. Antibiotic usage in the acute care setting: A cross sectional survey of Ontario hospitals. Canadian Society of Hospital Pharmacists: 29th Annual Professional Practice Conference. Toronto, February 5 to 9, 1998. (Poster) 


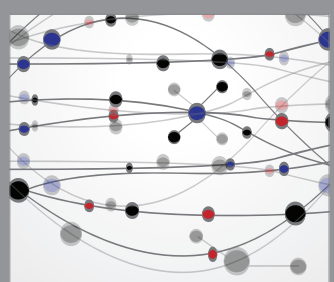

The Scientific World Journal
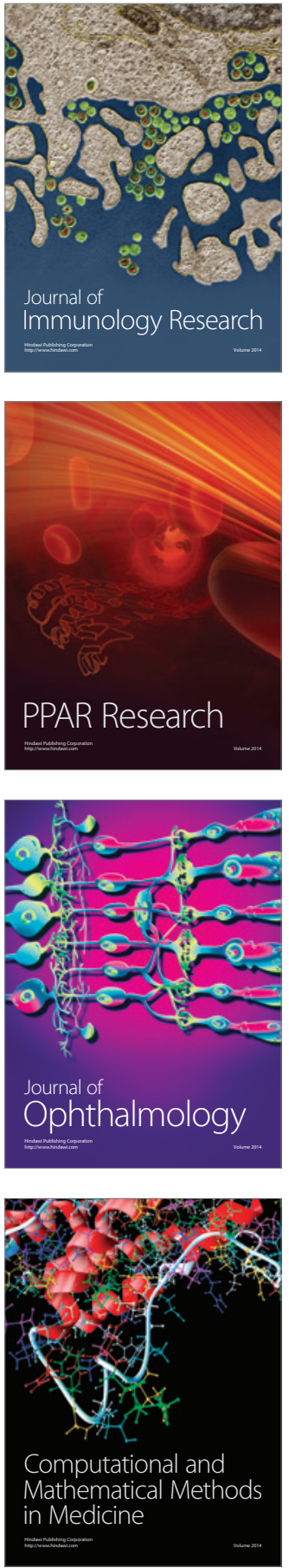

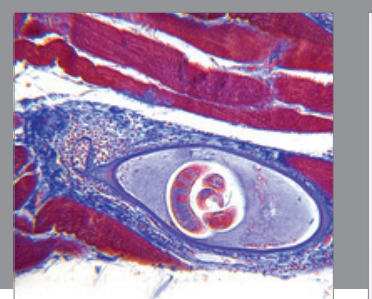

Gastroenterology Research and Practice

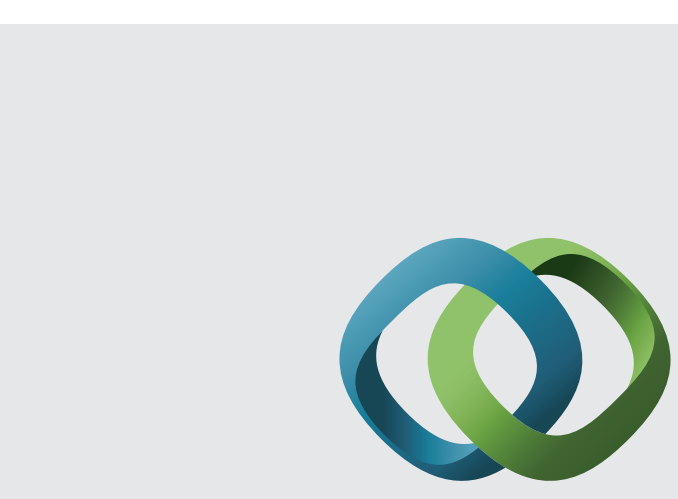

\section{Hindawi}

Submit your manuscripts at

http://www.hindawi.com
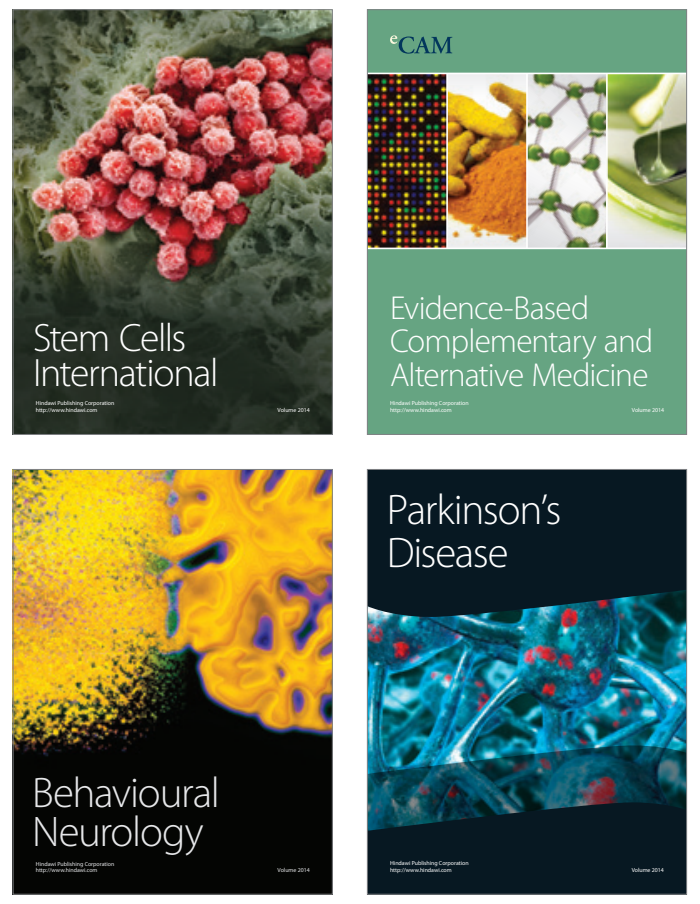
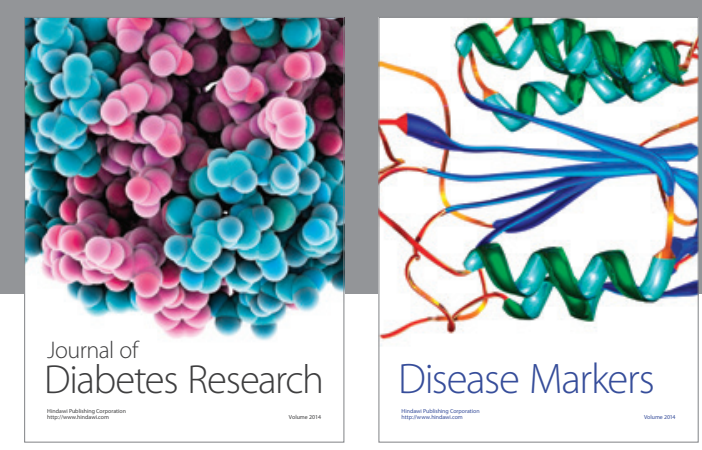

Disease Markers
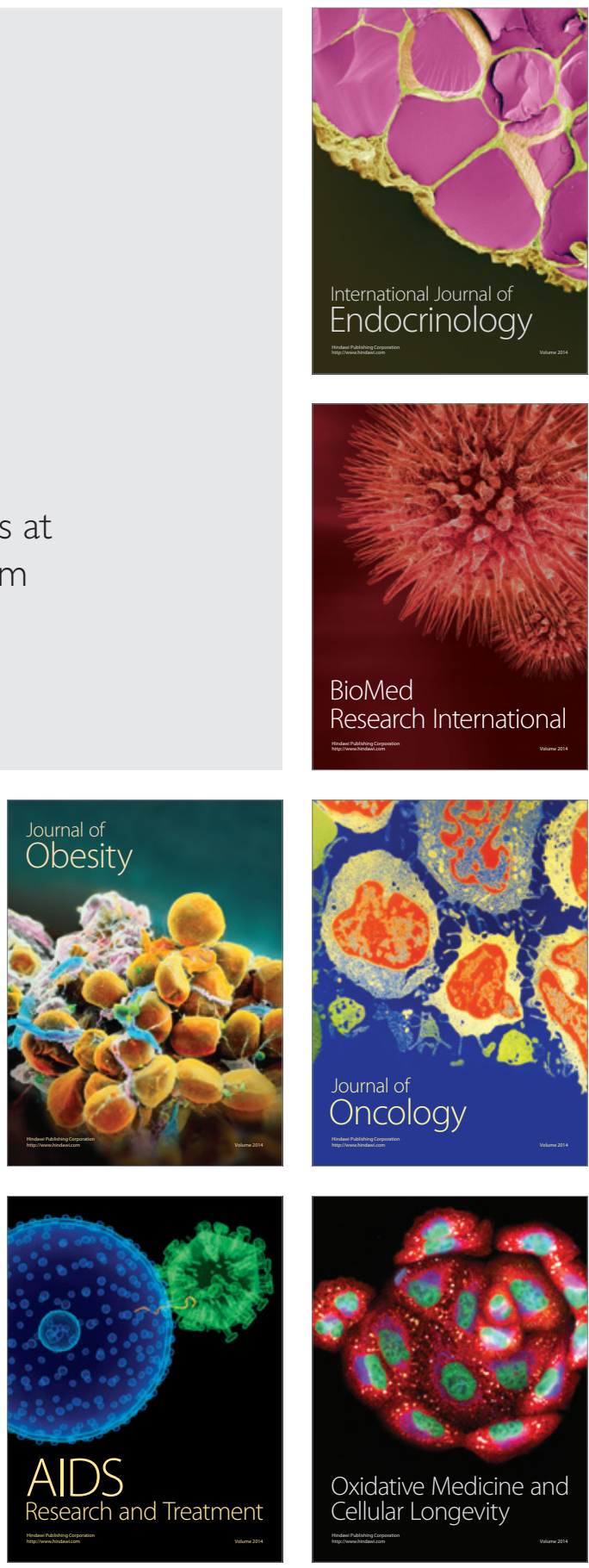